\title{
Construction Research of Newly Built Universities Developing Learning-Based Campus
}

\author{
Luo Xianfeng ${ }^{1, a}$ Gao Yonggui ${ }^{2}$ \\ ${ }^{1}$ Yibin Uiversity, Yinbin, Sichuan, China \\ 2.Yibin Vocational Technical College, Yibin ,Sichuan, China \\ a.1210687775@qq.com
}

\begin{abstract}
In recent years, universities teachers and students have blind, narrow, utilitarian, superficial, and miserable mood in study. This article puts forward that reconstructing learning beliefs, changing talent cultivation beliefs, and establishing learning model which are constructing learning campus to reach a realm of making people untied, making an innovation, learning campus under the circumstance .
\end{abstract}

Key words: learning beliefs, talent cultivation, learning model, learning-based university

\section{新建本科院校学习型校园建设研究}

\author{
罗先风 ${ }^{1, a}$ 高永贵 $^{2}$

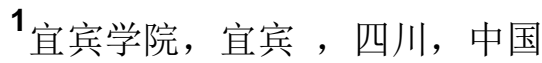 \\ 2 宜宾职业技术学院, 宜宾, 四川, 中国 \\ a $1210687775 @ q q . c o m$
}

中文摘要: 本文针对新建本科院校师生学习 中存在盲目、狭险、功利、肤浅、痛苦的现 状, 结合学习型校园建设的背景, 提出了学 习观念的重构、人才培养观念的转变、学习 模式的构建三种学习型校园建设的操作路 径, 以学习聚人心求创新促和谐, 臻于学习 型校园建设的新境界。

关键词: 学习观念 人才培养 学习模式 学习 型校园

\section{1. 引言}

在首届国际学习型城市在北京召开的背 景下, 积极响应并身体力行, 构建学习型校 园这一城市、社会细胞。为身在本科、分在 中游、能在下游的新建本科院校学生开拓一 条平凡而又不平常、输在起点赢在终点、后 来居上的成才之路。为人心浮躁、红尘滚滚 的新建本科院校教师探索一条“为天地立心、 为生民立命、为往圣继绝学、为万世开太平” 的以文化人、立德育人的心灵之道。

近年来，笔者对新建本科院校部分师生 
进行了走访, 发现部分师生在学习上存在以 下一些问题。一是学习很盲目。面对琳琅满 目、汗牛充栋的图书, 往往不是牛啃南瓜一 一开不了口, 就是捡到篮子都是菜一一无重 点之分。对开不了口的情况, 往往是东看看, 西焦焦, 拿不定主意, 下不了手。对捡到篮 子里的 “菜”，不管专业非专业、高雅低俗, 不分青红㿝白地乱读一气。二是学习很狭险。 重有字书轻无字书, 重书内知识轻书外信息。 只知去捉摸符号而不去研究符号所代表的意 义, 就只能了解字中的意思, 而不能看破字 外的妙理, 破解自然、社会、人生这本“天书”。 三是学习很功利。对部分学生而言, 学习的 目的是为了得高分, 为了得奖学金, 为了找 一个好工作, 为了衣食无忧, 对一些教师而 言, 学习为了评职称, 为了当干部, 为了过 上体面的生活。这是可以理解的。但是, 学 习的境界不高, 功利化、世俗化倾向非常严 重。如果这些目标都实现了的话, 学习可能 就会失去吸引力, 失去强大动力。四是学习 很肤浅。学习就学习, 两耳不闻窗外事, 以 致 “唯书中理论是瞻”, 不敢越雷池一步, 要 么食古不化, 以古非今, 要么全盘否定, 以 今非古。五是学习很痛苦。新建本科院校的 学生, 高考成绩往往都在中等偏上一点点, 对学习的爱好和成效是不敢恭维的。对学习 本身的重要性认识不够, 对自身能力估计不 足, 对苦乐观的辩证关系理解不深, 以致动 力不足, 不堪重负, 甚至精神恍惚, 谈 “学” 色变。一些教师也是 “学” 不关己, 高高挂 起。做一天和尚撞一天钟, 视学习为畏途, 视麻将为乐土。

\section{2.学习型校园建设的依据}

正是基于部分师生学习的现状和存在 的问题, 新建本科院校很有必要加强学习型 校园建设。学习型校园这一理念的提出, 源 于学习型组织的提出。1965 年, 美国佛瑞斯 特教授（Forrester）在他的著作《企业的 设计》中提出了学习型组织理论的维形。 1990 年, 彼得. 圣吉 (P. M. Senge) 在其著 作《第五修炼: 学习型组织的艺术与实务》 中正式系统地提出了学习型组织的理论, 认 为 “学习型组织是一个不断创新、进步的组 织, 在这个组织中, 大家需要不断突破自己
的能力上限, 创造真心向往的结果, 培养全 新、前瞻而阔的思考方式，全力实现共同的 抱负, 以及不断一起学习如何共同学习”。 2013 年 10 月 21 日, 由教育部联合国教科文 组织和北京市人民政府联合举办的首届学 习型城市大会在京召开, 提出了 “全民终身 学习: 城市的包容、繁荣和可持续发展” 为 主题, 通过了《建设学习型城市北京宣言》 和《学习型城市的重要特征》, 举办了以 “全 民终身学习是城市的未来” 为主题的市长论 坛以及 4 个地区平行论坛。这便为新建本科 院校学习型校园建设提供了契机, 擂响了战 鼓。

\section{3.学习型校园建设的目的和要求}

新建本科院校要以首届学习型城市建 设为契机, 将学习型校园作为学习型城市的 重要细胞, 纳入其中。践行新建本科院校的 人才培养、科学研究、社会服务和文化传承 创新四大职能, 突出教学中心任务, 高扬学 习型校园建设, 形成上下齐心, 师生齐学、 学中作乐、学有所成的良好氛围, 达到以学 习聚人心求创新促和谐的学习型校园建设 的目的。

再掀学习新革命。从终身学习、学习革 命、学习型社会到学习型城市, 学习的呼声 一浪高过一浪。高校作为学习的主战场, 深 省学习主任务, 高扬学习化生存, 再掀学习 新革命, 对聚人心求创新促和谐具有举足轻 重的作用。

聚焦学习主战场。瞄准学习主任务, 胸 怀天下, 心无旁檠, 聚精会神, 对准焦距, 向书本学习, 避免教条主义; 向实践学习, 避免经验主义; 向师长学习, 避免崇上唯上; 向外国学习, 避免崇洋媚外。以时不我待, 只争朝夕的精神真学、真懂、真用。

学会数字化生存。正确认识数字化学习 是什么; 改变自己, 适应数字化学习环境; 轻松驾驭, 利用好数字化学习资源; 学不单 行, 获取学习的支持服务; 反思评价, 为我 们的学习成效照镜子; 上下求索, 做成功的 修身学习者。

以学习聚人心求创新促和谐。以学习聚 人心, 围绕学习 “三比三看三发挥”, 即比 观念, 看谁的学习观念强; 比作用, 看谁的 
进取意识强; 比效果, 看谁的成效高, 领导 干部发挥表率作用, 教职工发挥骨干作用, 学生发挥生力军作用。以学习求创新, 围绕 “学以促读, 学以促写, 学以促研究”, 创 新学法, 学深学透, 不断创造新知, 不断推 陈出新。以学习促和谐, 这正是和谐校园建 设的题中之义, 是学习的最高境界, 所谓“为 万世开太平”, 构建和谐社会, 和谐世界。

\section{4.学习型校园建设的路径探索}

毛泽东同志曾说, “我们不但要提出任 务, 而且要解决完成任务的方法问题。我们 的任务是过河, 但是没有桥或没有船就不能 过。不解决桥和船的问题, 过河就是一句空 话。不解决方法问题, 任务也只是瞎说一顿”。 就新建地方院校实现 “学习型校园建设” 这 - “过河” 任务而言, 解决任务的方法有三, 一是学习观念的重构, 二是人才培养观念的 转变, 三是学习模式的构建。

\section{1 学习观念的重构: 让学习成为一种工作 和生活方式, 一种责任、一种心智模式。}

孔子说: “学而时习之, 不亦说乎。” 要 “学而不厌”, 要终身学习, 树立时时是学 习之时, 事事是学习之机, 处处是学习之所, 人人是学习之才, 以全新学习观念, 真正活 到老、学到老。让学习成为一种工作和生活 方式, 就是要将工作、生活与学习有机结合 起来, 做到工作学习化, 学习工作化; 生活 学习化, 学习生活化。只有让学习成为我们 的一种自觉行动, 一种自然而然的工作生活 方式, 才能学有所成、学有所乐、学有所用。 把学习当作一种责任, 就是要不断提升自身 的素质, 以便能胜任自己的工作, 完成党和 人民交办的任务。要带着使命、带着责任、 带着追求去学习。据有关资料统计, 18 世纪 以前, 知识更新的速度是 80-90 年翻一番, 到了 19 世纪 60 年代, 是 50 年左右翻一番, 到了 20 世纪 90 年代, 是 3-5 年翻一番。有 人说, 在农耕时代, 读几年的书, 可以管用 一辈子; 到了工业经济时代，读十几年的书 才能够用一辈子; 到了知识经济时代, 只有 终身学习, 才能够用一辈子。靠知识才能获 得能力、赢得尊重的大学校园, 知识分子把 学习当作一种责任更是情理之中的事。让学 习成为一种心智模式, 就是要通过学习, 改
善心智模式，烛照自己的内心，修正自己的 行动。黑格尔认为, 读书要跟着自己走, 并 坚持自己的信念。郁达夫说, 读书要有自己 的主见，所谓尽信书不如无书。意思是说， 学习要确立问题意识, 学习重在破解问题。 所谓 “心之官则思”, “学而不思则目, 思而 不学则怠”。有人说 “大河有水小河满”, 有 人却说 “小河有水大河满”, 这些都是关于 心智模式的问题。此外, 前人总结的 “筑巢 引凤”、“放水养鱼”、“今天工作不努力, 明 天努力找工作”、“我在发展你中发展了我, 你在塑造我中塑造了你” 等筬言都是改善心 智模式烛照内心的至理名言。可见学习型校 园建设, 首当其冲的是解放思想, 转变观念, 特别是学习观念的转变, 重构一种以乐学、 善学、可以烛照内心的全新的学习观念, 从 而为学习型校园建设提供不竭的思想动力 和精神支撑。

\section{2 人才培养观念的转变: 从 “理论学科型 人才” 向 “应用技术型人才” 转变。}

人才培养作为高校的重要职能之一, 新 建本科院校也必须高度重视。是培养书楃 式、书呆子式人才, 坐而论道, 还是以破解 问题为导向, 培养适应社会需要的技术型人 才, 这是不言自明的。然而, 要实现人才培 养观念的转变, 关键是学校, 核心在教师。 纵观新建本科院校, 师资专业结构偏重理论 学科型。很难想象, 理论学科型训练出来的 教师能培养出应用技术型人才。因此, 教师 的自我改造、自我提升、终身学习就提上了 议事日程。今年 3 月 22 日，2014 年中国发 展高层论坛上, 教育部副部长鲁昕在演讲中 谈到中国教育结构调整和现代职业教育时 透露，2000 年后 600 多所 “专升本” 的地方 本科院校将逐步转型, 做现代职业教育, 重 点培养工程师、高级技工、高素质劳动者。 据新华网 3 月 26 日消息, 已有部分地方政 府和近百所地方高校自愿报名参与, 可见, 人才培养方向的转向, 将促使新建本科院校 人才培养观念的转变, 由 “理论学科型人才” 向 “应用技术型人才” 转变。这也与我国即 将出台的高考方案相配套。据鲁昕在中国发 展高层论坛介绍, 第一种高考模式是技术技 能人才的高考, 第二种高考模式是学术型人 才的高考。新建本科院校的转型发展, 是国 
家发展的需要, 是现代职业教育升级增强的 需要, 也是面向市场, 适应市场经济发展的 需要。新建本科院校转型发展的过程, 是学 习、学习、再学习, 是不断完善学习型校园 建设的过程。

\section{3 学习模式的构建: 探索实践课外自能读 书模式。}

针对当前新建本科院校师生课外读书 活动的现状，笔者提出课外自能读书模式， 力求解决以上问题。所谓课外自能读书, 主 要包括三个方面的内涵: 即时间在课外, 自 觉是前提, 结合是关键, 做到 “四结合”, 即有字书与无字书相结合、专业书与非专业 书相结合、勤读与善思相结合、痛苦与快乐 相结合。一是有字书与无字书相结合。只有 把读有字书和无字书结合起来, 在读中悟, 在悟中读, 才是真正的读书, 才能读出书中 的精华, 才能读出书中的言外之意、弦外之 音, 才能读出真谛, 读出妙趣, 把自然、社 会和人生这部无弦琴弹出美妙绝伦的乐章 来。二是专业书与非专业书相结合。新建本 科院校, 学生都是分专业的, 课堂教学都是 以专业教学为主。大多数学生都只重视专业 学科知识的学习, 而对非专业学科知识, 则 认为可有可无。但是, 文科生需要学一点理 科方面的知识, 理科生需要读一点文史类的 书籍, 这已成为高校学人的共识。因此, 在 读好专业书籍的同时, 不妨且应该涉猎一些 非专业的领域, 所谓他山之石, 可以攻玉。 三是勤读与善思相结合。《论语》有云: “学 而不思则周, 思而不学则殆。” 换言之, 读 而不思则罔, 思而不读则殆。读书是进行思 考的基础, 思考是深入读书的手段。所谓读 以促思, 思以促读, 读思相长, 读思相连。 朱喜说: “读而未晓则思, 思而未晓则读。” 伏尔泰说: “书读得越多而不加思考, 你就 会觉得知道得很多, 而当你读书越多, 思考 越多的时候, 你就会清楚你知道得很少, 从 而更加努力。”说的正是这个道理。四是痛 苦与快乐相结合。读书苦不苦、乐不乐, 全 在于读书人的内心。在从有字书向无字书过 渡, 从有用阅读到无用阅读的延伸中, 我们 自然而然能体会到读书的快乐，以致手不释 卷, 废寝忘食, 乐而忘苦, 乐而忘忧, 读书 已回到与鸿儒、方家心灵的对话与沟通, 所
谓神交。在这种情况下, 书不是死书，人不 是死人。书读活了, 人也神清气爽。刘禹锡 在《陃室铭》中说, 婳室不陃, 原来是 “谈 笑有鸿儒, 往来无白丁”, 读好书就是与古 今中外 “鸿儒们” 促膝谈心, 何苦之有呢?

\section{5. 结束语}

本文针对新建本科院校师生学习中存 在盲目、狭险、功利、肤浅、痛苦的现状, 结合学习型校园建设的背景, 提出了学习观 念的重构、人才培养观念的转变、学习模式 的构建三种学习型校园建设的操作路径, 以 学习聚人心求创新促和谐, 臻于学习型校园 建设的新境界。

\section{致谢}

本文为四川省高等学校人文社会科学 重点研究基地一一新建院校改革与发展研 究中心项目《新建本科院校学习型校园建设 研究》 (XJYX2014B20) 的成果。

\section{References :}

[1] P.M. Senge. The fifth discipling:the art and practice of learning organization[M]. Translated by Guo Jinlong.Shanghai : Sanlian Bookstore, 1998.

[2] Zhou Yongliang, Li Jianli. Vocational Education Should Pay More Attention to Develop Students'Learning Ability. Vocational Education[J], 2007(18).

[3] Liu Jinmei. Taking about the Instructor Guide of Students'Extracurricular Reading[J]. Qing hai Education, 2013(2).

[4] Gao Baojun. Talking about the Significance and the Method of Extracurricular Reading[J]. New Course, 2013(4).

[5] Zhou Jing. Let Students Stroll in the"Spring Garden"of Extracurricular Reading[J]. Scientific Advisory,2013(29).

[6] Chen Xiuchun. Let the Extracurricular Reading Move towards the Light [J]. Study of Educational Curricular, 2013(18). 